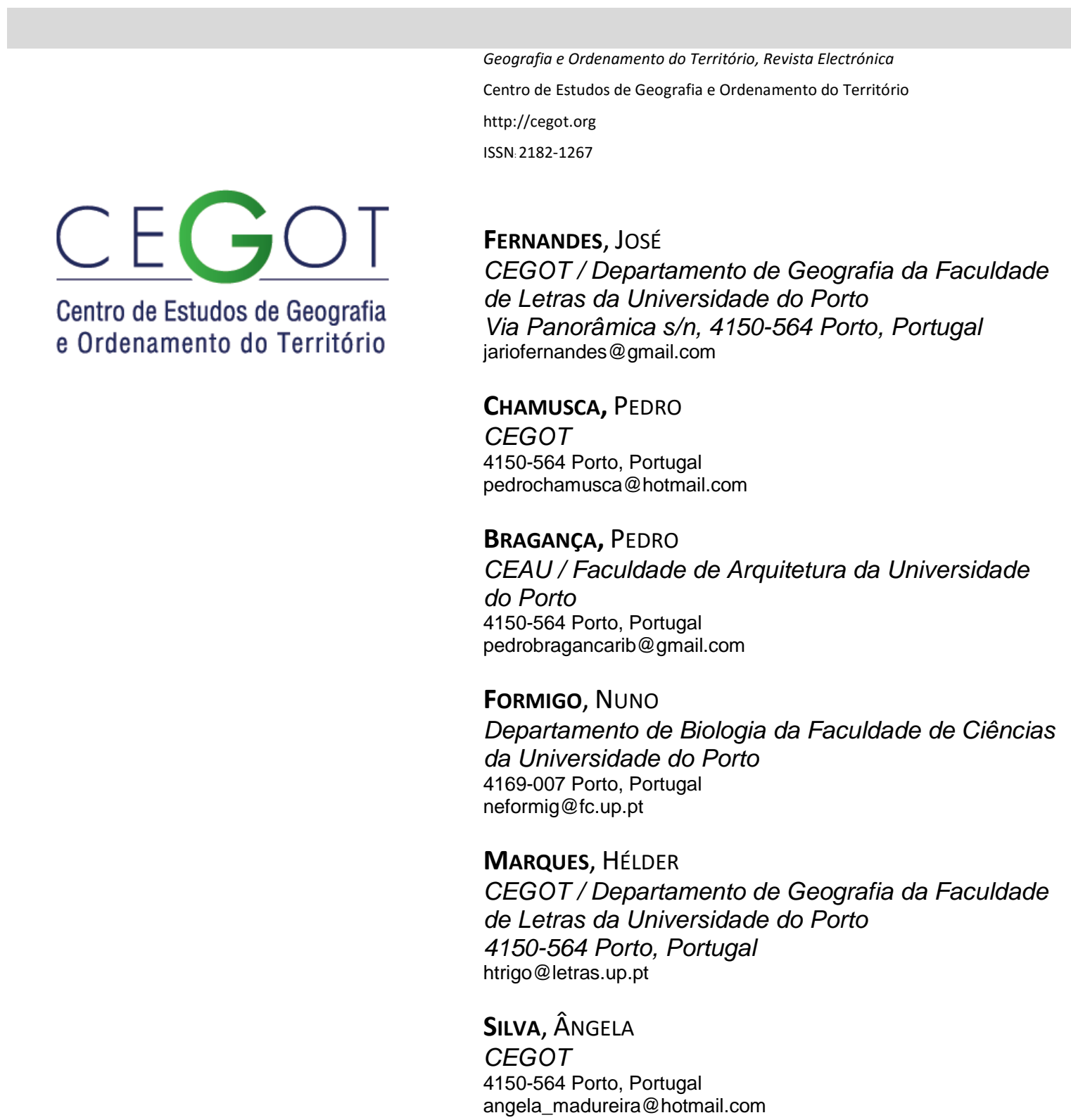

\title{
Aldeias de montanha: os problemas, as perspetivas e as propostas, vistos desde as serras da Aboboreira, Marão e Montemuro, no Noroeste de Portugal
}

Mountain villages: problems, perspectives and proposals as seen from Aboboreira, Marão and Montemuro in the Northwest of Portugal

Referência: Fernandes, José et al. (2016). Aldeias de montanha: os problemas, as perspetivas e as propostas, vistos desde as serras da Aboboreira, Marão e Montemuro, no Noroeste de Portugal. Revista de Geografia e Ordenamento do Território (GOT), n. 9 (junho). Centro de Estudos de Geografia e Ordenamento do Território, p. 113-137, dx.doi.org/10.17127/got/2016.9.006 


\section{RESUMO}

Com poucas exceções, as aldeias que persistem vivas e que se encontram numa localização marcada pela condição periférica e de (muito) baixa densidade, estão marcadas por um contexto de despovoamento, com exceções pontuais de atração de neo-rurais ou visitantes. É nesse contexto que, em espaço de montanha, porventura ultraperiférico e de muito baixa densidade que, para o caso de aldeias das serras de Marão, Aboboreira e Montemuro, se realizou um trabalho que pretende dar apoio a opções políticas. É desse trabalho e em especial da sua metodologia que aqui se dá conta, esperando-se contribuir para um debate - há muito iniciado - a propósito da vantagem em estabelecer opções de base territorial e de ser seletivo nos investimentos, tendo em vista a manutenção e revitalização de alguns pontos de fixação que permitam manter o povoamento e o uso socialmente vantajoso de grandes espaços.

Palavras-chave: aldeia, montanha, desenvolvimento rural

\section{ABSTRACT}

With few exceptions, villages that remain at a location marked by the peripheral conditions and (very) low density are marked by a context of depopulation, despite some cases, here and there, of more or less successful examples in attracting neo rural inhabitants or visitors. It is in this context that, in a mountain space, perhaps ultra-peripheral and of very low density that, in the case of the villages of Marão, Aboboreira and Montemuro villages, work has been carried on, aiming to provide support to policy options. In this paper we present this work and in particular its methodology, hoping to contribute to a debate - which started long time ago - on the advantages of establishing options and being selective in the investments for the maintenance and revitalization of some key points that allow to maintain the population and the socially advantageous use of large spaces.

Keywords: village, mountain, rural development

\section{Metropolização, urbanização do rural e qualidade de vida em}

\section{territórios de baixa densidade}

Pode ser visto de acordo com perspetivas muito diversas o modo como o processo de urbanização ocorreu na Europa ao longo das últimas décadas, transformando significativamente quer as relações entre cidade e campo, quer mesmo o que ancestralmente os caracterizava.

Uma forma possível de sintetizar um processo necessariamente complexo e que adquire matizes diversos de acordo com a escala e o lugar a partir do qual o vemos, passa por considerar uma visão fundamentalmente demográfica (figuras 1 e 2), tendo por pano de 
fundo o conceito e processo de desenvolvimento, nos seus âmbitos económico, ambiental e social.

Olhando os fluxos que animam o processo de urbanização, pode falar-se de um prolongado êxodo rural, em que, tal como há mais de um século, os mais jovens e qualificados procuram os lugares de maior conectividade na economia mundial, os quais proporcionarão melhores condições potenciais para a inovação económica, terão uma maior capacidade de produção de riqueza e oferecerão mais e melhores oportunidades de emprego. Neste movimento, causa e consequência da fixação das instituições públicas e privadas de maior alcance político, social, económico e cultural nas cidades de grande dimensão, ocorre em paralelo uma atração muito significativa dos que vêm das periferias (vistas agora à escala mundial), num processo de aumento da dimensão e complexidade dos maiores espaços urbanos. A este propósito, vários autores têm dado conta dum processo de metropolização associável à integração global das economias, em que alguns grandes centros parecem atuar como pivot de vastas regiões urbanas (ou predominantemente urbanas), porventura fisicamente descontínuas, todavia por vezes melhor articulados com metrópoles longínquas do que com alguns espaços de baixa densidade que podem estar a menos de uma hora de distância (Ascher, 2002; Hall, 1996; Hall, 2014; Sassen, 2006).

Neste quadro, é hoje comummente aceite que a antinomia conceptual que durante séculos estabeleceu uma clara diferenciação entre territórios urbanos e rurais perdeu uma grande parte da sua validade científica (pelo menos em boa parte do Hemisfério Norte), verificando-se também que a diversidade paisagística e da base económica dos territórios de baixa densidade formatou territorialidades muito distintas entre si.

Na Europa e em particular em Portugal é muito clara a distinção face aos demais de alguns lugares, mais dinâmicos, onde o produtivismo da Política Agrícola Comum teve condições para singrar, o que terá sido favorecido pela grande dimensão das parcelas, especialização das produções, motorização e rejuvenescimento ou capacidade empresarial. Aí emergiram clusters competitivos, territorialmente confinados, quase sempre ligados a uma dada fileira. Paralelamente, aumentou não apenas a terciarização que resultou do reforço da presença do Estado Social, traduzida desde logo na importância dos equipamentos de educação e apoio social, como os serviços especializados de apoio à produção ou ligados ao consumo, animados pelo aumento do poder de compra da generalidade da população. Outros lugares, em resultado de combinações diversas de handicaps específicos (morfológicos, de capital humano, ou devidos a excentricidade geográfica, por exemplo), quedaram-se numa 
economia marcadamente agro-silvo-pastoril de base camponesa, tendo sofrido um esvaziamento demográfico especialmente forte, a par de um acentuado envelhecimento populacional, o que, no limite, levou ao seu completo abandono. De facto, em Portugal, e um pouco por toda a Europa Mediterrânica, onde o mundo rural suportou, pelo menos até à década de cinquenta do século passado, percentagens de população ativa no setores primário muito elevadas, onde o povoamento foi marcada por aldeias densas e compactas, as perdas demográficas têm sido muito significativas nas últimas décadas e, por regra, tanto maiores, em peso relativo, quanto menor é a dimensão populacional dos aglomerados.

Nuns e noutros casos, entre uma variedade de situações que faz de cada aldeia um caso específico, é inegável que o campo tem incorporado nas últimas décadas, à medida que foi esmorecendo o isolamento, alguns dos atributos tradicionalmente definidores do urbano, os quais se evidenciam quer no modo de vida, quer nas condições de acesso a bens e serviços. Por isso, não existe atualmente uma cultura rural, mas sim culturas muito diversas, agora híbridas, sem que isso implique que, de uma ou de outra forma, contaminem práticas simbólicas, tidas como ancestralmente definidoras da especificidade do campo. Acresce que o recente impacte da presença dos neo-rurais pode ter sido até agora negligenciado, até porque a procura das amenidades rurais foi recorrentemente lida como continuidade da contracultura soissente huitard, ou de modo geral da New Left que emergiu no decorrer dos anos 60 do século passado e não como oportunidade de recomposição do capital humano e de regeneração do tecido produtivo.

Um estudo recente (Pinto, 2015), justamente realizado no território "Douro Verde" (Amarante, Baião, Cinfães, Marco de Canaveses e Resende), mostrou que para a maioria dos neo-rurais entrevistados (num total de 35 ) a motivação ambiental, ou de um modo geral, a valorização das amenidade rurais, tende a ser complementar da procura de oportunidades de inserção no tecido produtivo. Mas mostrou também que a "rutura" com o urbano não é absoluta, na medida em os respondentes valorizam a posição de franja metropolitana e destacam a pequena distância tempo em relação ao Porto. Além disso, são essencialmente provenientes do "Grande Porto", bem mais academicamente qualificados e jovens do que a população residente, evidenciando ainda um elevado capital relacional e boa capacidade empreendedora, com enlaces às estruturas associativas locais. Boa parte revela ainda a importância de rendibilização da herança patrimonial e justifica racionalmente (pelo acesso a financiamento comunitário, por exemplo) a opção por sistemas produtivos mais agro 
ecológicos, no âmbito de práticas agrícolas pós produtivistas, associadas nomeadamente ao modo de produção biológico e ao turismo em espaço rural (Marques, 2015).

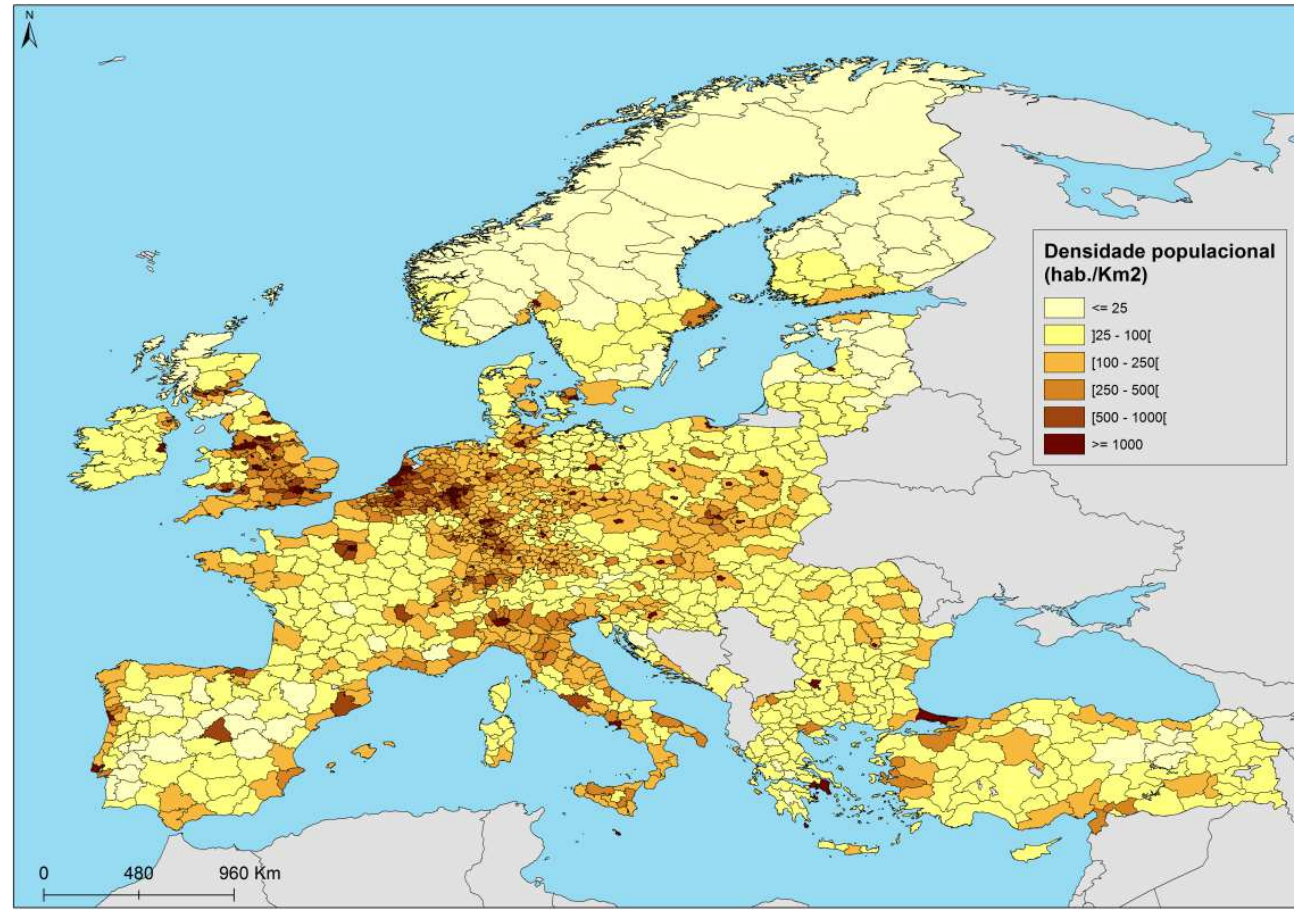

Figura 1 - Densidade populacional na Europa, por NUTS III (2010) Fonte: Eurostat

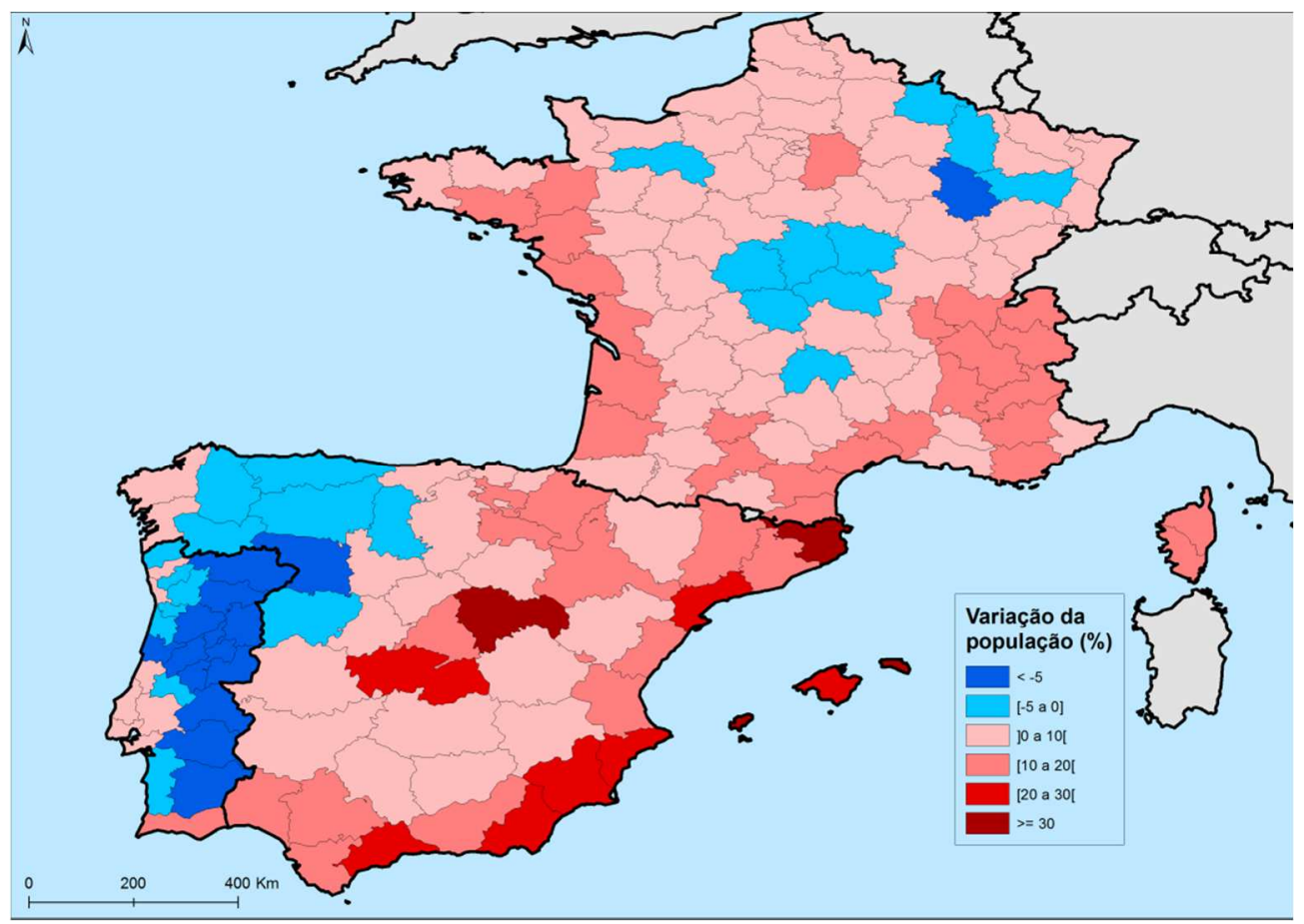

Figura 2 - Variação da população residente (2002-2014), por NUTS III em Portugal, Espanha e França. Fonte: Eurostat 


\section{O desafio do desenvolvimento, visto desde o Norte de Portugal}

Durante muito tempo, desenvolvimento foi confundido com crescimento, demográfico primeiro, económico depois. Ora, verifica-se que nalguns dos países considerados como entre os mais desenvolvidos, como a Noruega, não existem grande metrópoles e é possível ter excelente qualidade de vida em espaços de baixa densidade. Ao contrário, algumas das cidades mais populosas e regiões de elevadíssima densidade populacional, como Lagos (na Nigéria) ou Dacca (no Bangladesh), não garantem condições de vida digna à maioria dos seus habitantes, ainda que vejam a sua população aumentar muito mais que as cidades consideradas em diversos rankings como aquelas que oferecem melhores condições de vida (onde Adelaide, Zurique e Vancouver regra geral se salientam).

Por isso, a generalidade dos autores e muitos dos relatórios de orientação política, das Nações Unidas, da OCDE e da Comissão Europeia, por exemplo, reconhecem a importância menor da quantidade de habitantes e conferem cada vez mais significado a outras dimensões além da capacidade de produção de riqueza, associando ao desenvolvimento além da dimensão económica, a social e ambiental, a que alguns acrescentam a qualidade da governança (que pode ser visto alternativamente como condição para os anteriores).

A dimensão social pressupõe o acesso a serviços essenciais e a existência de laços que evitem a exclusão e garantam condições de dignidade que, ainda que sejam garantidas de forma diferente de acordo com a pessoa e o lugar, sejam no essencial idênticas às que são asseguradas à generalidade dos habitantes de um país que tenham idêntica necessidade. Este desafio coloca-se especialmente nas áreas de características mais marcadamente rurais, com baixas densidades populacionais, mais excêntricas e com uma morfologia serrana, onde a ocupação do solo remete, em grande medida, para a gestão de matos e florestas e para a manutenção de práticas agropecuárias de baixa intensidade. Aí, a elevada espessura temporal do "isolamento", ao mesmo tempo que permitiu a afirmação de marcas de identidade paisagística a relevar de forma qualitativa, coloca desafios especialmente difíceis dada a fragilidade social, enquanto a dimensão cultural é muito radicada em valores de assunção coletiva de base imaterial, de memórias e de representações idiossincráticas.

Relativamente à dimensão ambiental, a avaliação é cada vez mais feita em termos do tipo e qualidade dos serviços de ecossistema que um dado território é capaz de prestar, entendidos simultaneamente, numa perspectiva individual, centrada na importância de cada um, e numa perspectiva integrada, que considera a relação existente entre os vários 
tipos de serviços que são prestados. Vários projetos internacionais têm, em particular nos últimos 20 anos, procurado desenvolver as ferramentas para esta avaliação, no quadro de uma tendência consolidada para favorecer um ordenamento do território assente em mosaicos de diferentes tipos de ocupação de solo que, ao proporcionarem diferentes combinações dos vários serviços de ecossistema prestados, se associam a paisagens ambientalmente mais sustentáveis, geradoras de uma melhor qualidade de vida para os que nelas habitam.

Do ponto de vista da governança, este tipo de avaliação permite fornecer ao decisor político cenários de intervenção, priorizados em termos de relação custo benefício ambiental e social dos investimentos a efetuar (Tudor, 2014; Bianchin et al, 2011; Dale et al, 2013; Everard \& Waters, 2013; Jellinek et al, 2013; Opdam et al, 2013). Considera-se, além disso, que os territórios de baixa densidade são especialmente adequados para as lógicas de governança, a que soma a compreensão da maior pertinência da aplicação de outras das dimensões do desenvolvimento, seja pelo reconhecimento da importância acrescida que pode ter uma liderança esclarecida e mobilizadora, seja pelos efeitos muito significativos que resultam da colaboração entre os principais agentes envolvidos no processo de desenvolvimento (CCE, 2001; Healey, 2004; OCDE, 2006; ODPM, 2003; Silva, 2011).

No caso do Norte de Portugal, fora do arco metropolitano do Porto (definido entre Viana, Amarante e Aveiro), do eixo urbano Vila Real-Régua-Lamego e de algumas sedes de concelho, o decréscimo populacional, em lugares onde os efetivos populacionais já eram reduzidos (figura 3), foi especialmente forte, sendo acompanhado de um processo de envelhecimento que atinge taxas muito elevadas. Os desafios são por isso também maiores, importando desde logo traçar objetivos. Entre visões de modernização "inevitável" ou nostálgico "regresso ao passado" ou de um embelezamento turistificante, o debate é aceso. Antes, importa contudo analisar recursos, compreender as mudanças e considerar os programas e projetos em curso. Importa ainda entender que, a nada ser feito, a tendência ao abandono por muitos de velhas práticas agrícolas (pastorícia, agricultura de subsistência, aproveitamento de vários produtos das matas e florestas) será provavelmente seguida de uma florestação com recurso a espécies de crescimento rápido (eucalipto, sobretudo), com o consequente aumento dos incêndios florestais, degradação do potencial ecológico e despovoamento populacional. 
O contexto é desafiante, mas também adequado à possibilidade de promoção e gestão de paisagens com um maior equilíbrio dos serviços de ecossistema que fornecem, garantindo sustentabilidade a médio e longo prazo, favorecendo a criação de mais valias ambientais associáveis a mais valias económicas e sociais, assentes em novas formas de fruição, não só em termos turísticos, sobretudo de turismo de base ambiental ligado ao usufruto de uma natureza mais preservada, mas também a novos nichos de mercado para a exploração comercial, sustentável e sustentada, de produtos diversos.

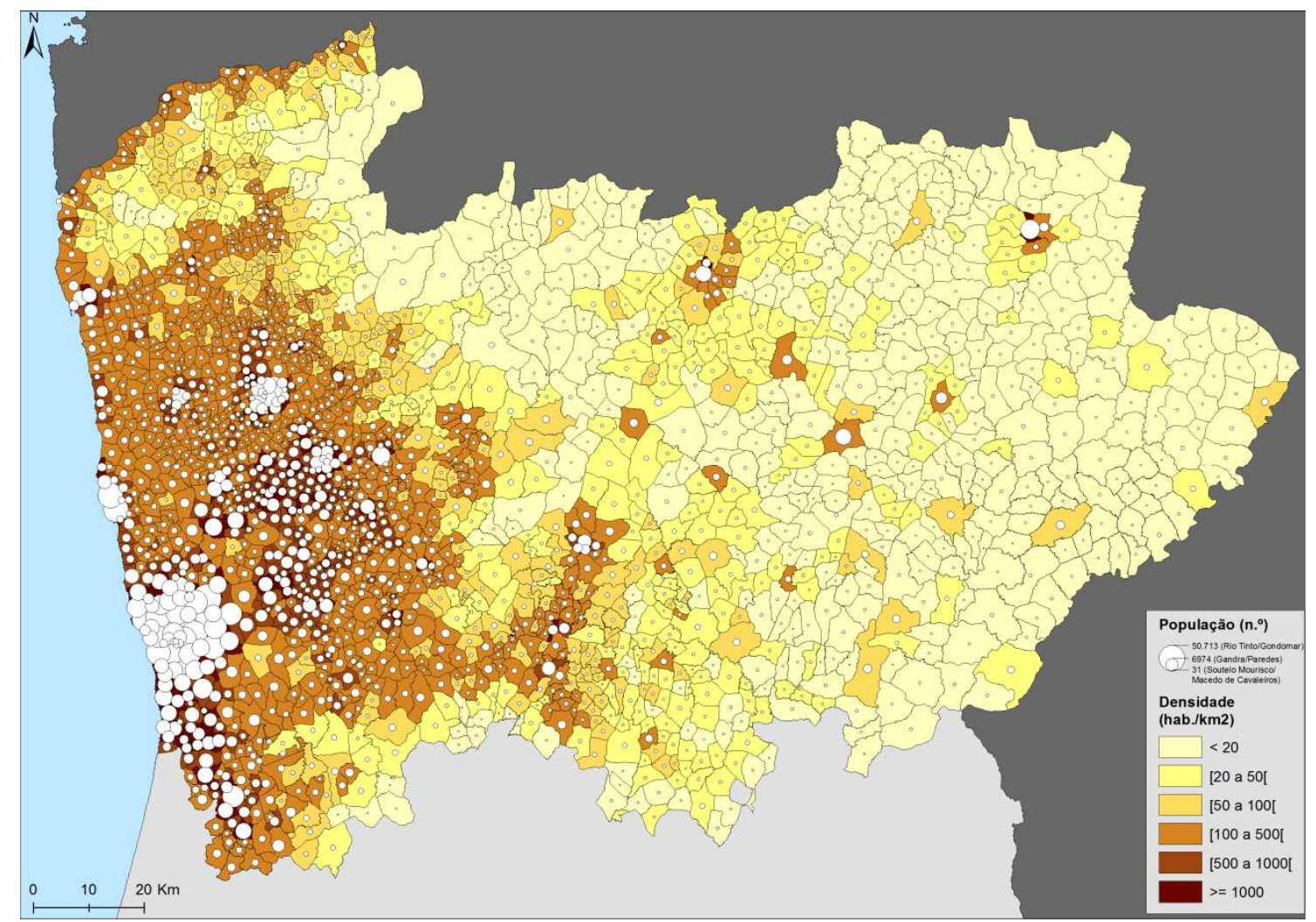

Figura 3 - População residente e densidade populacional no Norte de Portugal, por freguesia (2011) Fonte: INE

A esta perspetiva, em que questões de natureza ambiental se inserem no desenvolvimento de base territorial, somam-se dimensões sociais e económicas, interrelacionadas com a anterior e entre si, as quais, com boa governança, estão na base do projeto "Aldeias com Vida", de que adiante se dá conta. Todas revelam oportunidades, como se depreende do que ficou dito, seja pela lógica económica pós-produtivista e ecológica que ganha terreno, seja na dimensão social, onde velhos e novos nexos de solidariedade acrescentam valor e a internet ou telefone facilitam o acesso a serviços essenciais e acessórios. 


\section{A tendência e as alternativas}

Os problemas que se colocam em espaços periféricos de baixa densidade e em especial nas aldeias localizadas a grande altitude, têm motivado uma intensa busca de possibilidades de ação, com acesos debates na comunidade científica e, em geral, um sentimento de perda e de desvalorização produtiva e cultural que tem levado ao desenvolvimento de vários projetos de revitalização de base territorial.

Soliva et al. (2008) estudaram várias experiências europeias (na Escócia, Eslováquia, França, Grécia, Noruega e Suíça) para concluírem que o elemento central de qualquer abordagem de desenvolvimento local nestes espaços se deve centrar no envolvimento dos cidadãos. Consideram que estratégias que não promovam uma participação e empoderamento efetivos dos agentes locais terão uma reduzida capacidade de sucesso, podendo inclusivamente despoletar ou agravar conflitos variados, designadamente na propriedade e uso do solo.

Os quatro cenários apresentados para o horizonte de 2030 colocam o foco da aposta na produção agrícola, sublinhando que as comunidades instaladas têm maior propensão para adotar estratégias que promovam a multifuncionalidade, a biodiversidade e a conversão da paisagem, em detrimento de aposta de liberalização ou industrialização da atividade agrícola. Shucksmith e Rønningen (2011) acrescentam que os pequenos espaços de produção desempenham um papel central na sustentabilidade das economias rurais, constituindo um fator de alavancagem de estratégias de base local. Estas ideias têm merecido ampla discussão, designadamente no Reino Unido, onde a última década tem sido fértil na análise de cenários de desenvolvimento para estes territórios. Reed et al. (2009) sintetizam estes estudos, dando conta da importância atribuída às questões da habitação, da produção agrícola, do turismo e da preservação ambiental.

A especificidade dos territórios de baixa densidade, de matriz rural, bem como as particularidades que apresentam, cada um e em cada país, leva a que as experiências de política pública se multipliquem, num contexto genericamente marcado por uma grande incerteza. Se em Portugal são várias as iniciativas interessantes (ainda que não exclusivamente para aldeias de montanha) ligadas a uma certa revitalização - de que são exemplo as Aldeias do Xisto, as Aldeias Históricas de Portugal, as Aldeias de Montanha, as Aldeias da Saudade, a Aldeia do Futuro, o Projeto Querença, o Projeto Barril, o movimento 
Novos Povoadores, ou a rede Aldeias com Futuro, de que falaremos no ponto seguinte a propósito do Marão, da Aboboreira e do Montemuro - noutros casos merece destaque a dimensão imobiliária. Por exemplo, em Espanha, o Jornal El País noticiava em agosto de 2015 a existência de cerca de 3500 aldeias abandonadas, um pouco por todo o país, das quais cerca de 1500 tinham já sido vendidas ou colocadas no mercado, com preços que variavam entre os 20 mil e os vários milhões de euros. Esta abordagem tem revelado algum sucesso, motivando inclusivamente uma empresa dedicada exclusivamente a este tipo de negócio e com grande notoriedade (http://www.aldeasabandonadas.com/), onde vários municípios e proprietários particulares (estes em maior número), apresentam aldeias (de montanha ou não) para venda ou, no caso das autoridades públicas, para repovoamento e criação de condições de dinamização económica. O mesmo tipo de processo ocorre em Itália, entre outros países, onde aldeias com castelo se comercializam ao preço de um apartamento em Londres, conforme noticiava o britânico The Mirror em março de 2015.

Na Grécia tornou-se muito conhecida a aldeia de Anavra, devido a uma iniciativa promovida pela comunidade local que fez deste pequeno povoamento de montanha um dos mais ricos do país, capaz de prosperar mesmo num período de crise. Michailidou (2012) identifica o envolvimento da comunidade e a aposta na produção de energia (a produção eólica é suficiente para 13000 habitantes e gera lucros anuais na ordem dos 100 mil euros) e na agricultura, como as principais razões para o sucesso da estratégia de base local. Destaca ainda a importância da oferta de vários benefícios aos seus residentes, como eletricidade, aquecimento e estacionamento gratuitos e ainda o livre acesso a ginásios, escolas, museus, parque ambiental-cultural e espaços para a prática de desporto. O resultado é uma população residente de 500 habitantes, muito envolvida no planeamento e gestão da aldeia, com idade média inferior a 40 anos e um rendimento anual per capita que oscila entre os 30 e os 100 mil euros, proveniente quase exclusivamente da atividade agrícola.

Globalmente, o que se considera como sucesso aparece quase sempre associado a novas formas de uso do solo e à mobilização dos recursos naturais locais, privilegiando-se a sustentabilidade ambiental, com aproveitamento de energia eólica, desenvolvimento de agricultura biológica ou ecologicamente equilibrada e existência de uma atividade turística associado a uma paisagem qualificada. 


\section{As aldeias de Marão, Aboboreira e Montemuro: estudo de caso}

O projeto "Aldeias Com Futuro"1 foi desenvolvido nas serras do Marão, Aboboreira (com Castelo) e Montemuro entre setembro de 2014 e julho de 2015, com apoio de fundos comunitários do PROVERE - Programa de Valorização Económica de Recursos Endógenos, tendo como objetivo a construção de uma intervenção futura, capaz de articular investimento público e privado. Tratou-se de um projeto-piloto que pretendeu avaliar o valor das aldeias serranas e as suas possibilidades de desenvolvimento, procurando, em articulação com a associação de desenvolvimento local Dolmen, construir a base de uma estratégia orientada para crescimento económico e social. Além do trabalho central de avaliação, procurou-se definir formas de promover a valorização dos recursos endógenos dos espaços de baixa densidade localizados nas altitudes mais elevadas e de melhorar as condições para a sustentabilidade ambiental e social e para a competitividade e diversificação da atividade económica. No momento em que escrevemos o presente texto, o projeto aguarda disponibilidade de verbas, no âmbito do Portugal 2020, para iniciar uma segunda fase, de implementação e concretização de projetos.

\section{Metodologia}

O projeto assentou numa metodologia de aproximação sucessiva que considerou a relevância da dimensão populacional das aldeias, as suas condições de acessibilidade, o valor investido (em infraestruturas, equipamentos e construções, designadamente) e, em especial, a possibilidade de estas deterem a capacidade que lhes permita não apenas fixar e atrair habitantes, como criar valor a favor dos seus residentes e da região.

A abordagem estruturou-se em três fases - pré-seleção, seleção e estudo piloto.

\section{Pré-seleção}

O estudo partiu da consideração de todas as aldeias existentes nas serras da Aboboreira/ Castelo, Marão e Montemuro. Para a realização de uma primeira filtragem (de pré-seleção)

\footnotetext{
${ }^{1}$ Toda a informação sobre o projeto, incluindo relatórios de caracterização, metodologia e proposta estão disponíveis no sítio da internet www.aldeiascomfuturo.com, plataforma colaborativa criada no âmbito do projeto. O projeto foi realizado pelos autores do presente texto e também por Inês Fernandes, contando ainda com a colaboração de Frederico Alves.
} 
foram definidos três critérios, considerados como indicadores do perfil e dinâmica da aldeia: altitude, excentricidade e população, devendo situar-se acima dos 600 metros, localizar-se a uma distância superior a 10 quilómetros relativamente à sede do concelho e registar mais de 50 habitantes no último censo (2011).

Para a pré-seleção das aldeias, optou-se por estabelecer como orientação a eliminação de todas as aldeias que não cumpriam dois dos três critérios estabelecidos, o que resultou na eliminação de cinco aldeias (tabela 1).

\begin{tabular}{|c|c|c|c|c|c|c|c|c|c|c|c|c|c|}
\hline \multicolumn{14}{|c|}{ ABOBOREIRA/CASTELO } \\
\hline & Almofrela & \begin{tabular}{|c|}
$\begin{array}{c}\text { Carvalho de } \\
\text { Rei }\end{array}$ \\
\end{tabular} & $\begin{array}{r}\text { Charras } \\
\text { ra }\end{array}$ & & Cruzeiro & Guarda & & $\begin{array}{l}\text { ivos do } \\
\text { Monte }\end{array}$ & Quintela & São Tiago & $\begin{array}{cc}\text { Travanca do } & \text { Ven } \\
\text { Monte } & \text { Gie } \\
\end{array}$ & sta & Vinheiros \\
\hline Altitude & 800 & 700 & & 700 & 700 & & & 700 & 50 & 550 & 800 & 550 & 650 \\
\hline Distância à sede de concelho & 4,70 & 13,40 & & 9,50 & 9,00 & & & 9,30 & 8,9 & 9,50 & 15,40 & 8,20 & 10,20 \\
\hline População residente & 22 & 51 & & 46 & 78 & & 3 & 74 & 5 & 20 & 89 & 53 & 31 \\
\hline \multicolumn{14}{|c|}{ MARÃO } \\
\hline \multicolumn{5}{|c|}{ Canadelo } & \multicolumn{2}{|c|}{$\begin{array}{l}\text { Covelo do } \\
\text { Monte }\end{array}$} & \multicolumn{2}{|c|}{ Granja } & \multicolumn{2}{|c|}{ Mafómedes } & Murgido & \multicolumn{2}{|c|}{ Póvoa } \\
\hline \multicolumn{2}{|l|}{ Altitude } & \multicolumn{3}{|c|}{300} & \multirow{2}{*}{\multicolumn{2}{|c|}{$\begin{array}{r}600 \\
20,00\end{array}$}} & \multicolumn{2}{|r|}{700} & \multicolumn{2}{|r|}{800} & 700 & \multicolumn{2}{|r|}{700} \\
\hline \multicolumn{2}{|c|}{ Distância à sede de concelho } & \multicolumn{3}{|c|}{16,50} & & & & 24,80 & & 17,60 & \multirow{2}{*}{\begin{tabular}{r|}
24,20 \\
236 \\
\end{tabular}} & \multicolumn{2}{|r|}{25,90} \\
\hline \multicolumn{2}{|l|}{ População residente } & & & 21 & \multicolumn{2}{|r|}{103} & & 55 & & 35 & & & 180 \\
\hline \multicolumn{14}{|c|}{ MONTEMURO } \\
\hline \multirow{2}{*}{\multicolumn{2}{|c|}{ Altitude }} & \multicolumn{2}{|c|}{\begin{tabular}{|l|l} 
Alhões & \\
1000
\end{tabular}} & \multicolumn{2}{|c|}{ Bustelo } & \multicolumn{2}{|c|}{ Fermentãos } & \multicolumn{2}{|c|}{ Gralheira } & Meridãos & Quinhão & \multicolumn{2}{|c|}{ Panchorra } \\
\hline & & \multirow{2}{*}{\multicolumn{2}{|c|}{\begin{tabular}{r|}
1000 \\
21,50
\end{tabular}}} & \multicolumn{2}{|r|}{850} & \multicolumn{2}{|c|}{800} & \multicolumn{2}{|r|}{1100} & 650 & \multirow{2}{*}{\begin{tabular}{r|}
700 \\
10,00
\end{tabular}} & \multicolumn{2}{|r|}{1100} \\
\hline \multicolumn{2}{|c|}{ Distância à sede de concelho } & & & & 19,70 & & 2,10 & & 28,00 & 9,80 & & & 18,30 \\
\hline População residente & & & 181 & & 112 & & 114 & & 165 & 116 & 121 & & 82 \\
\hline
\end{tabular}

Tabela 1 - Aldeias validadas durante o processo de pré-seleção.

\section{Seleção}

A seleção das aldeias esteve associada aos trabalhos de levantamento funcional e registo e caracterização dos seus recursos. Para o efeito considerou-se a recolha e tratamento de informação estatística e o trabalho de campo, com: a) entrevistas aos residentes; b) inventariação e georreferenciação de todos os elementos de caracterização; c) identificação do regime de posse do solo nas aldeias e espaço envolvente, de cultivo, pastoreio, florestação e inculto; e d) caracterização pormenorizada de todas as infraestruturas e equipamentos de serviço coletivo.

A ficha de levantamento de campo incluiu sete dimensões de análise relativos a:

- Localização, altitude e caraterização demográfica e social;

- Tipo de paisagem, considerando a presença de matos, floresta, área agrícola, tecido urbanizado e ainda os vários corredores existentes;

- Recursos hídricos, em especial cursos de água; 
- Infraestruturas, considerando as redes de serviço/abastecimento, as vias rodoviárias e aspetos ligados à sinalização;

- Edificado, considerando o sistema construtivo, o sistema de cobertura, o processo histórico, o tipo de ocupação e o estado de conservação;

- Atividades económicas, com registo de elementos associados ao comércio e serviços (incluindo a venda ambulante), bem como aspetos do sistema produtivo relacionados com a produção agropecuária e florestal e sua comercialização;

- Equipamentos, incluindo um conjunto alargado de elementos de uso coletivo.

A recolha, tratamento e georreferenciação destes elementos serviu de base ao desenvolvimento de dois exercícios de seleção das aldeias. O primeiro consistiu na consideração de todos os elementos recolhidos, com normalização de dados (numa escala em que o valor mais elevado corresponde a " 1 " e o valor mais reduzido a " 0 ", com todos os restantes calculados proporcionalmente). Este exercício foi realizado de forma independente para cada uma das serras, apontando para uma maior importância das aldeias de Gralheira no Montemuro e de Canadelo no Marão, ainda que aqui se tenha destacado também Murgido. Na serra da Aboboreira/Castelo verificou-se um maior equilíbrio com Travanca do Monte, Carvalho de Rei e Loivos do Monte a apresentarem valores muito próximos (tabela 2).

ABOBOREIRA/CASTELO

\begin{tabular}{|l|c|}
\hline Travanca do Monte & 27,03 \\
\hline Carvalho de Rei & 26,98 \\
\hline Loivos do Monte & 26,81 \\
\hline Cruzeiro & 24,63 \\
\hline Guarda & 18,97 \\
\hline Vinheiros & 15,39 \\
\hline
\end{tabular}

Tabela 2 - Resultado da consideração e normalização de todos os elementos
MONTEMURO

\begin{tabular}{|l|l|l|l|l|}
\hline Canadelo & 32,87 & & Gralheira & 38,72 \\
\hline Murgido & 31,47 & Alhões & 32,15 \\
\hline Covelo do Monte & 24,58 & & Bustelo & 30,36 \\
\hline Granja & 24,32 & Fermentãos & 26,78 \\
\hline Póvoa & 24,21 & Meridãos & 26,36 \\
\hline Mafómodes & 21,23 & & Panchorra & 23,29 \\
\cline { 1 - 2 } & & Quinhão & 19,15 \\
\hline
\end{tabular}

O segundo exercício considerou onze critérios-chave, selecionados em função da sua importância para a compreensão das dinâmicas sociais, económicas e ambientais. Aos três critérios utilizados na fase de pré-seleção juntaram-se as questões associadas à população jovem, às qualificações, à ocupação dos alojamentos, aos equipamentos e infraestruturas 
básicas existentes, à taxa de emprego e aos estabelecimentos de comércio e serviços existentes, o que permitiu também, em articulação com a análise do setor económico dominante no emprego formal, associar a cada aldeia um perfil tipo: agropecuário ou florestal; turístico; ou tendencialmente urbano (tabela 3).

\begin{tabular}{|c|c|c|}
\hline \multirow{4}{*}{$\begin{array}{l}\frac{0}{0} \\
\frac{\pi}{0} \\
\frac{\pi}{U} \\
0 \\
0\end{array}$} & População residente & $>=50$ \\
\hline & $\%$ de jovens (- de 20 anos) & $>=15$ \\
\hline & $\%$ da pop. com pelo menos o ensino secundário & $>=15$ \\
\hline & $\%$ de alojamentos vagos & $<=15$ \\
\hline \multirow{4}{*}{ 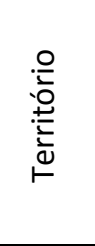 } & Altitude & $>=600 \mathrm{~m}$ \\
\hline & Distância à sede do concelho (Km) & $>=10$ \\
\hline & Infraestruturas básicas existentes & $>=5 / 9$ \\
\hline & Equipamentos existentes & $>=11 / 21$ \\
\hline \multirow{3}{*}{ 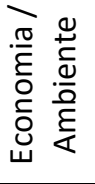 } & \% da população com 15 e + anos empregada & $>=25$ \\
\hline & Tipos de comércio existentes (fixo + ambulante) & $>=7 / 14$ \\
\hline & Tipos de serviços existentes & $>=4 / 7$ \\
\hline
\end{tabular}

Tabela 3 - Critérios chave

O resultado deste exercício apresentou algumas diferenças relativamente ao anterior. Se, no Montemuro, Gralheira continuou a evidenciar-se - aliás destacou-se novamente em todo o território - e, na Aboboreira/Castelo, Travanca do Monte e Carvalho de Rei voltam a ocupar os lugares principais, no caso do Marão esta abordagem sugere que o estudo piloto se faça em Granja ou Murgido (tabelas 4, 5 e 6).

\begin{tabular}{|c|c|c|c|c|c|c|}
\hline & $\begin{array}{c}\text { Carvalho de } \\
\text { Rei }\end{array}$ & $\begin{array}{c}\text { Travanca do } \\
\text { Monte }\end{array}$ & Guarda & $\begin{array}{c}\begin{array}{c}\text { Loivos do } \\
\text { Monte }\end{array} \\
\end{array}$ & Vinheiros & Cruzeiro \\
\hline População residente & 51 & 89 & 23 & 74 & 31 & 78 \\
\hline$\%$ de jovens (- de 20 anos) & 17,65 & 16,85 & 21,74 & 28,38 & 16,13 & 30,77 \\
\hline$\%$ da pop. com pelo menos o ensino secundário & 15,56 & 8,00 & 31,82 & 3,45 & 20,00 & 5,45 \\
\hline$\%$ de alojamentos vagos & 27,27 & 11,76 & 21,74 & 16,67 & 0,00 & 4,76 \\
\hline Altitude & 700 & 800 & 750 & 700 & 650 & 700 \\
\hline Distância à sede do concelho (Km) & 13,3 & 15,2 & 14,5 & 9,2 & 10,1 & 9 \\
\hline Infraestruturas básicas existentes & 5 & 5 & 5 & 5 & 4 & 4 \\
\hline Equipamentos existentes & 9 & 5 & 3 & 5 & 2 & 4 \\
\hline$\%$ da população com 15 e + anos empregada & 29,17 & 49,37 & 27,27 & 34,43 & 13,79 & 20,34 \\
\hline Tipos de comércio existentes (fixo + ambulante) & 4 & 4 & 5 & 4 & 4 & 6 \\
\hline Tipos de serviços existentes & 2 & 1 & 0 & 0 & 0 & 0 \\
\hline Setor económico dominante (emprego formal) & Secundário & Secundário & Terciário & Secundário & Terciário & Secundário \\
\hline \multirow[t]{2}{*}{ Economia dominante (observação) } & Urbana & Turismo & Urbana & Urbana & Turismo & Urbana \\
\hline & $7 / 11$ & $7 / 11$ & $6 / 11$ & $5 / 11$ & $5 / 11$ & $4 / 11$ \\
\hline
\end{tabular}

Tabela 4 - Resultado da análise de critérios-chave na Aboboreira/Castelo 


\begin{tabular}{|c|c|c|c|c|c|c|}
\hline & Granja & Murgido & $\begin{array}{c}\begin{array}{c}\text { Covelo do } \\
\text { Monte }\end{array} \\
\end{array}$ & Póvoa & Canadelo & Mafómodes \\
\hline População residente & 55 & 236 & 103 & 180 & 121 & 35 \\
\hline$\%$ de jovens (- de 20 anos) & 27,27 & 18,22 & 24,27 & 12,78 & 10,74 & 0,00 \\
\hline$\%$ da pop. com pelo menos o ensino secundário & 14,58 & 6,86 & 2,22 & 5,42 & 8,77 & 7,41 \\
\hline$\%$ de alojamentos vagos & 11,11 & 6,83 & 10,64 & 11,97 & 12,50 & 20,83 \\
\hline Altitude & 700 & 700 & 600 & 700 & 300 & 800 \\
\hline Distância à sede do concelho (Km) & 24,7 & 23,3 & 20 & 25,3 & 16,5 & 17,6 \\
\hline Infraestruturas básicas existentes & 5 & 6 & 4 & 5 & 6 & 6 \\
\hline Equipamentos existentes & 2 & 5 & 3 & 3 & 6 & 4 \\
\hline$\%$ da população com $15 \mathrm{e}+$ anos empregada & 44,44 & 29,56 & 30,00 & 33,74 & 25,66 & 14,29 \\
\hline Tipos de comércio existentes (fixo + ambulante) & 5 & 6 & 4 & 5 & 5 & 7 \\
\hline Tipos de serviços existentes & 0 & 2 & 1 & 0 & 2 & 1 \\
\hline Setor económico dominante (emprego formal) & Secundário & Secundário & Terciário & Secundário & Terciário & Terciário \\
\hline \multirow[t]{2}{*}{ Economia dominante (observação) } & Urbana & Urbana & Agr./Flor./Pec. & Urbana & Agr./Flor./Pec. & Turismo \\
\hline & $7 / 11$ & $7 / 11$ & $6 / 11$ & $6 / 11$ & $5 / 11$ & $4 / 11$ \\
\hline
\end{tabular}

Tabela 5 - Resultado da análise de critérios-chave no Marão

\begin{tabular}{|c|c|c|c|c|c|c|c|}
\hline & Gralheira & Bustelo & Fermentãos & Meridãos & Quinhão & Alhões & Panchorra \\
\hline População residente & 165 & 112 & 114 & 116 & 121 & 181 & 82 \\
\hline$\%$ de jovens (- de 20 anos) & 16,36 & 19,64 & 21,93 & 10,34 & 13,22 & 14,92 & 13,41 \\
\hline$\%$ da pop. com pelo menos o ensino secundário & 13,57 & 5,77 & 10,87 & 21,00 & 16,07 & 11,46 & 5,80 \\
\hline$\%$ de alojamentos vagos & 0,46 & 0,93 & 11,61 & 0,89 & 9,57 & 15,97 & 2,42 \\
\hline Altitude & 1100 & 850 & 800 & 650 & 700 & 1000 & 1100 \\
\hline Distância à sede do concelho (Km) & 27,8 & 19,7 & 12,1 & 9,8 & 12,4 & 21,5 & 18,3 \\
\hline Infraestruturas básicas existentes & 7 & 5 & 7 & 5 & 5 & 6 & 3 \\
\hline Equipamentos existentes & 11 & 9 & 4 & 6 & 6 & 10 & 7 \\
\hline \% da população com 15 e + anos empregada & 32,88 & 37,76 & 36,46 & 28,30 & 31,53 & 25,00 & 22,54 \\
\hline Tipos de comércio existentes (fixo + ambulante) & 7 & 7 & 7 & 7 & 3 & 6 & 6 \\
\hline Tipos de serviços existentes & 2 & 0 & 0 & 0 & 1 & 0 & 0 \\
\hline Setor económico dominante (emprego formal) & Terciário & Primário & Terciário & Terciário & Terciário & Terciário & Secundário \\
\hline Economia dominante (observação) & Turismo & Agr./Flor./Pec. & Agrícola/Florestal & Urbana & Urbana & Agr./Flor./Pec. & Turismo \\
\hline & $9 / 11$ & $8 / 11$ & $8 / 11$ & $7 / 11$ & $7 / 11$ & $5 / 11$ & $4 / 11$ \\
\hline
\end{tabular}

Tabela 6 - Resultado da análise de critérios-chave no Montemuro

A seleção final resultou do cruzamento destes dois exercícios e da consideração da vantagem em considerar aldeias: a) das três serras; b) de vários municípios; e c) com diferentes perfis, considerando o destaque do turismo, a relevância da agropecuária, ou aa penetração urbana. Em função destas preocupações e dos resultados obtidos foi criada uma matriz de possibilidades que ajudou a fundamentar a seleção das seguintes aldeias (tabela 7; figura 4), o que foi validado por representantes políticos e outros agentes da região com interesse nas serras em geral e nas aldeias em particular. 


\begin{tabular}{|c|c|c|c|c|c|c|}
\hline \multirow[b]{2}{*}{$\begin{array}{c}\mathbf{E 1} \\
\text { (todos os } \\
\text { elementos) }\end{array}$} & \multicolumn{2}{|l|}{ H1 } & \multicolumn{2}{|l|}{ H2 } & \multicolumn{2}{|l|}{ H3 } \\
\hline & $\begin{array}{l}\text { Gralheira/Panchorra } \\
\text { Canadelo } \\
\text { Loivos do } \\
\text { Monte/Cruzeiro }\end{array}$ & $\begin{array}{r}38,7 \\
32,9 \\
26,8 \\
\mathbf{9 8 , 4}\end{array}$ & $\begin{array}{l}\text { Gralheira/Panchorra } \\
\text { Travanca do Monte } \\
\text { Murgido/Granja/Póvoa }\end{array}$ & \begin{tabular}{|l|}
38,7 \\
27 \\
31,5 \\
$\mathbf{9 7 , 2}$
\end{tabular} & $\begin{array}{l}\text { Travanca do Monte } \\
\text { Alhões } \\
\text { Murgido/Granja/Póvoa }\end{array}$ & $\begin{array}{r}27 \\
32,2 \\
31,5 \\
\mathbf{9 0 , 7}\end{array}$ \\
\hline $\begin{array}{c}\mathbf{E 2} \\
\begin{array}{c}\text { (critérios- } \\
\text { chave) }\end{array}\end{array}$ & $\begin{array}{l}\text { Gralheira/Panchorra } \\
\text { Travanca do Monte } \\
\text { Murgido/Granja/Póvoa }\end{array}$ & $\begin{array}{r}99 \\
7 \\
7 \\
23\end{array}$ & $\begin{array}{l}\text { Carvalho de Rei ou } \\
\text { Travanca do Monte } \\
\text { Bustelo } \\
\text { Murgido/Granja/Póvoa }\end{array}$ & $\begin{array}{r}8 \\
7 \\
22\end{array}$ & $\begin{array}{l}\text { Gralheira/Panchorra } \\
\text { Covelo do Monte } \\
\text { Loivos do } \\
\text { Monte/Cruzeiro }\end{array}$ & $\begin{array}{r}9 \\
6 \\
5 \\
20\end{array}$ \\
\hline
\end{tabular}

Tabela 7 - Matriz de cruzamento de resultados e orientações estratégicas

\section{Estudo piloto}

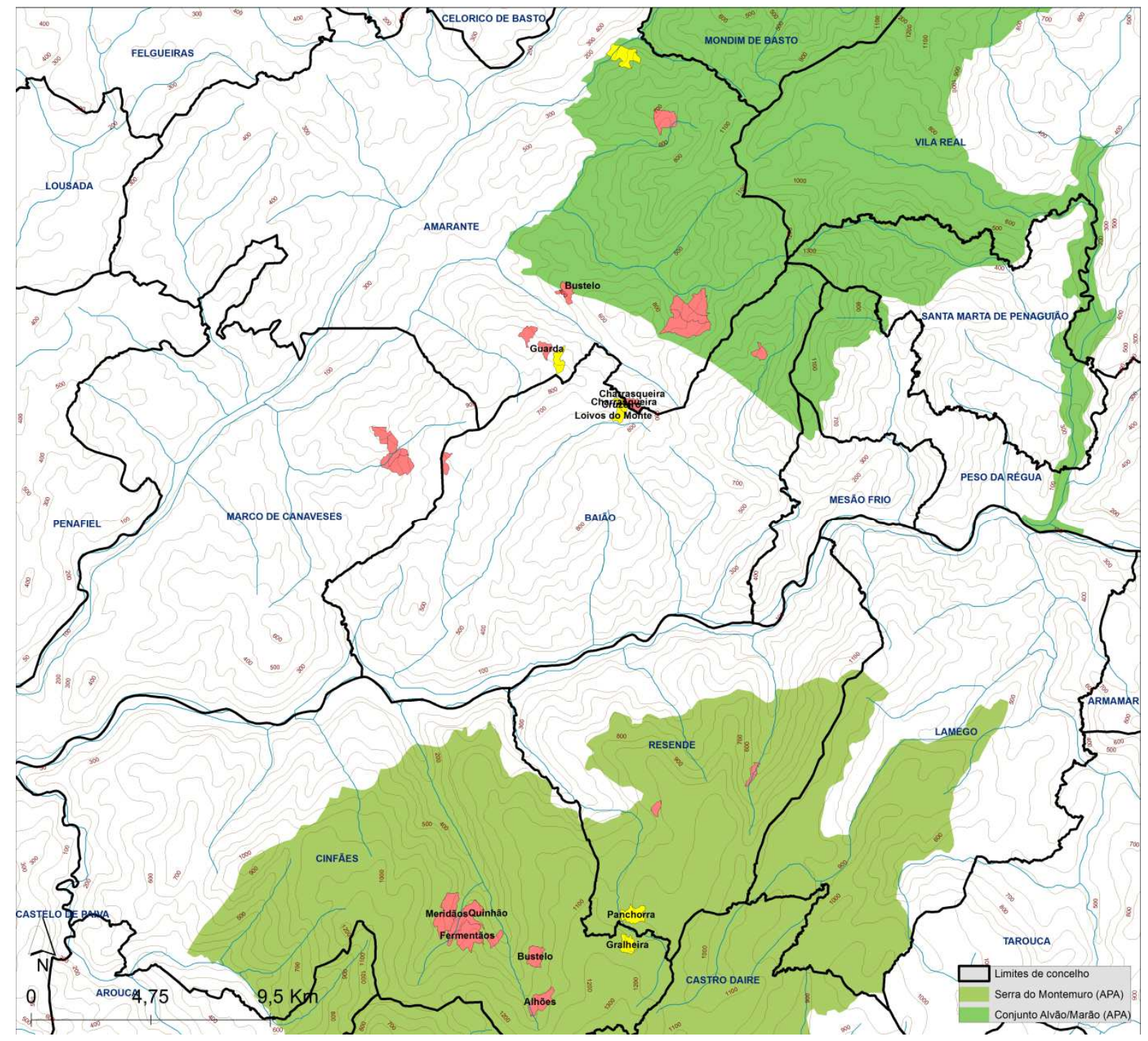

Figura 4 - Localização das aldeias selecionadas para o estudo piloto 
O desenvolvimento de um estudo piloto e a definição de estratégias territoriais partem da consideração prévia de três cenários de desenvolvimento. O primeiro está associado a uma intervenção mínima, prevendo que se mantenham as tendências atuais. Foi designado de "esperar para ver". O segundo prevê a introdução de medidas que preparem ou antecipem o despovoamento, devendo associar-se a situações de excecionalidade: é o "preparar ou antecipar o despovoamento". O terceiro diz respeito a uma opção clara de revitalização, com mobilização de investimento público e privado, respeitoso das especificidades da aldeia e capaz de mobilizar soluções com elevado potencial: "agir para desenvolver".

A avaliação de valores e recursos foi considerada como central para a definição de uma estratégia de desenvolvimento territorial, estabelecendo-se três dimensões: social, ambiental e económica.

A análise dos valores sociais compreendeu quatro parâmetros. O primeiro está associada a indicadores de natureza demográfica, considerando o peso dos mais jovens e dos mais idosos e a variação da população residente. O segundo centra-se na interajuda informal, ligada quer ao lar quer ao trabalho (existência ou não de vezeiras ou simples troca de trabalho), ou gestão partilhada do património comum (utilização coletiva de eiras, fornos ou gestão de baldios). A vinculação à aldeia é o terceiro, observando a ligação afetiva, a auto estima da comunidade, o impacto do associativismo e ainda o papel dos emigrantes. Por fim, o quarto parâmetro diz respeito aos valores culturais e simbólicos que transparecem em festas ou outros eventos lúdicos (danças, cantares, etc.) e nos conhecimentos e memórias, como os oralmente transmitidos, ou nas técnicas e saber fazer dos residentes.

A compreensão dos valores ambientais implicou a análise de elementos do património natural e construído. Para o primeiro são consideradas espécies de fauna, flora, geologia e recursos hídricos; no segundo considera-se a antiguidade e o valor formal do edificado e o conforto do espaço público.

O terceiro grupo de valores - de natureza económica - foi avaliado através de três dimensões. A primeira compreende o escrutínio do edificado e das infraestruturas, considerando a dinâmica de construção, a percentagem de edifícios em condições de habitabilidade e as infraestruturas rodoviárias, de eletricidade, água e saneamento. A segunda circunscreve-se à análise do sistema produtivo, avaliando o valor associado à atividade agropecuária (comercial e de autoconsumo) e florestal. Finalmente, promoveu-se 
uma avaliação de outras atividades económicas, a partir dos estabelecimentos e empresas industriais e de comércio e serviços instalados.

Para todos os indicadores de análise, nos três sistemas de valores, é definido um quadro de avaliação - qualitativa e quantitativa -, traduzido numa pontuação que tem quatro escalas de valor. Quer isto dizer que a avaliação final de qualquer um dos indicadores oscila entre uma pontuação de 4 (muito relevante) a 1 (pouco relevante), considerando o desempenho da aldeia. Por exemplo, no caso de indicadores totalmente quantitativos, como por exemplo a taxa de variação da população, foi atribuída uma avaliação de 4 a todas as aldeias com desempenho melhor do que o país (taxa de variação de 1,99\% entre 2001 e 2012); uma avaliação de 3 a todas as aldeias com variação positiva, mas inferior à média nacional; de 2 a todas as aldeias com perda populacional até 10 pontos percentuais; e de 1 aos povoamentos com perdas superiores a $10 \%$. No caso de indicadores qualitativos, a avaliação traduz a importância do indicador. Por exemplo, a apreciação do peso da agropecuária para autoconsumo resultou numa avaliação em que 4 corresponde a muito importante; 3 a importante; 2 a pouco importante; e 1 a nada importante, numa escala que ao contrário da anterior não traduz uma uniformização, antes retratando a importância de determinado indicador ou recurso.

O cruzamento dos três cenários de desenvolvimento com o sistema de valores de uma aldeia constitui uma importante ferramenta de apoio à tomada de decisão, em especial de apoio à definição de estratégias que promovam sinergias e ganhos de eficácia e eficiência na utilização dos resíduos. Da metodologia desenvolvida resulta a proposta de que deve ser o sistema de valores a definir o cenário adequado para cada aldeia e, consequentemente, o programa estratégico de intervenção, ainda que, naturalmente, articulado com as vontades e programas políticos sufragados. Em concreto, assume-se que o cenário ou a estratégia de desenvolvido para cada aldeia deve considerar como central uma aposta nos valores identificados, seja para potenciar o seu aproveitamento e a geração de mais-valias para o território, seja para a atenuação de alguns constrangimentos e criação de valor.

O primeiro cenário - "Esperar para ver" - associou-se a aldeias com pontuação intermédia nos três grupos de valores, ou com duas pontuações intermédias e uma baixa (figura 5). 

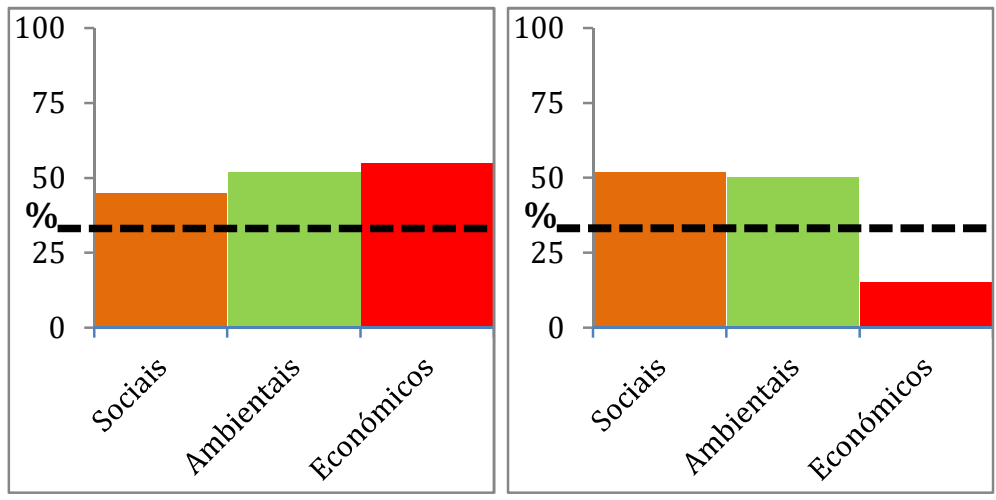

Figura 5 - Perfis tipo associados ao cenário "Esperar para ver"

O segundo cenário - de preparação ou antecipação do despovoamento - está associado a situações extremas, em contextos territoriais com uma pontuação baixa em dois ou três dos grupos de valores (figura 6).
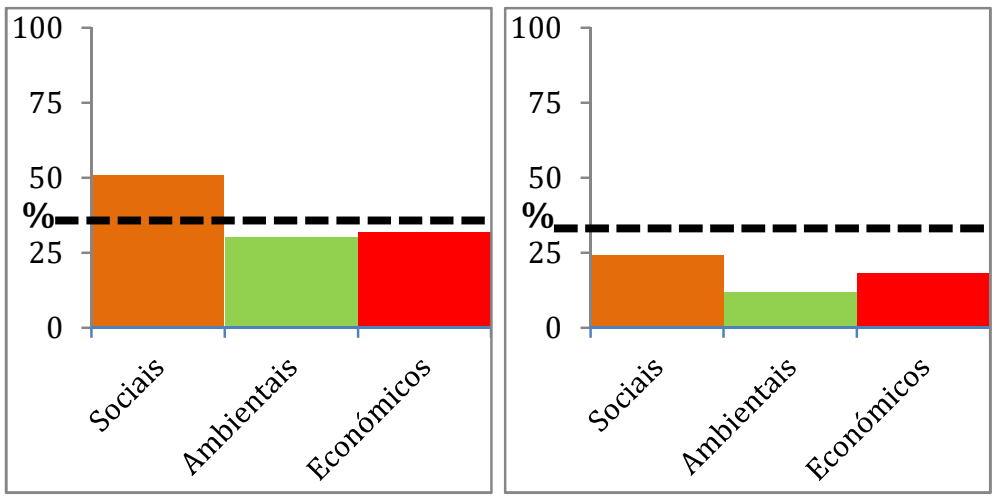

Figura 6 - Perfis tipo associados ao cenário "Preparar/antecipar o despovoamento"

O terceiro cenário - agir para desenvolver - associa-se a espaços que reúnem um conjunto elevado de recursos e valores, podendo ainda acontecer que um dos grupos de valores apresenta fragilidades (figura 7). Neste cenário assume-se como prioritária a intervenção para correção de todas as situações problemáticas (pontuação baixa), a par da potenciação dos pontos mais fortes (pontuação elevada). 

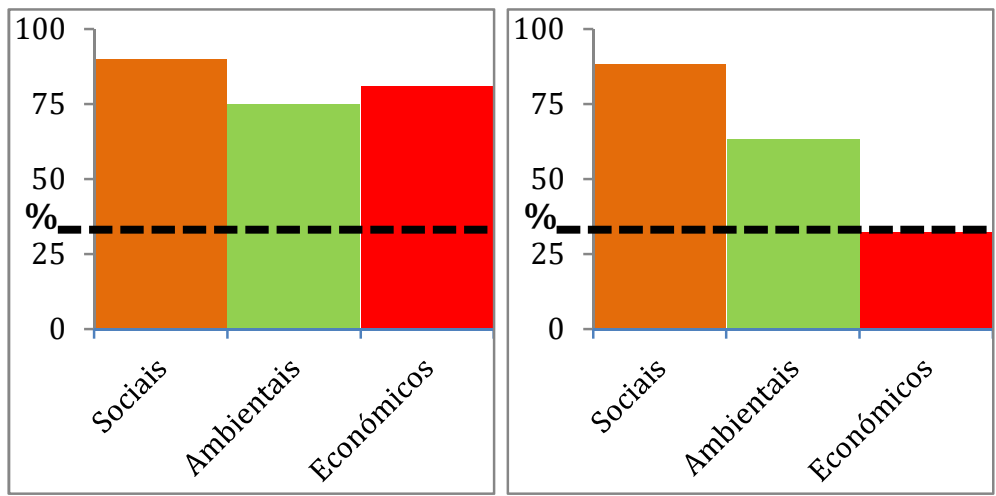

Figura 7 - Perfis tipo associados ao cenário "Agir para desenvolver"

\section{Resultados}

O cruzamento dos três cenários de desenvolvimento com o sistema de valores traduziu-se em resultados muito diversos, ainda que todas as aldeias apresentem potencialidades que permitem enquadrá-las no cenário de ação que recomenda o estímulo ao desenvolvimento (figura 8).

Há um claro destaque da aldeia da Gralheira, na serra do Montemuro e concelho de Cinfães, com a identificação de um conjunto elevado de valores nas três dimensões. As questões ambientais são, contudo, as que mais se destacam, o que se verifica também em Panchorra (também no Montemuro, no município de Resende) ou em Travanca do Monte (em Amarante, na serra da Aboboreira). Nas restantes aldeias, os valores e recursos são considerados menos relevantes, destacando-se a dimensão social em Cruzeiro e Loivos do Monte (lugares contíguos, em Baião, na Serra da Aboboreira/Castelo) e a dimensão económica em Canadelo (município de Amarante, serra do Marão).

Em detalhe, verificamos que na aldeia de Canadelo há uma especial incidência dos recursos ambientais e económicos. Os valores sociais observados (com pontuação ligeiramente superior a 50\%) estão associados a uma forte vinculação à aldeia - com um movimento associativo dinâmico e uma relação forte da comunidade emigrante - e à existência de valores culturais relevantes, designadamente festas e eventos. Os indicadores demográficos evidenciam perda. No domínio ambiental destacam-se os valores associados aos recursos hídricos e geológicos. O património construído regista o valor de alguns edifícios e do conjunto, designadamente do valor estético da relação do povoamento com a paisagem. 0 
sistema de valores económicos é o mais forte, apesar do défice verificado na dimensão das atividades económicas, em contraponto com uma forte dinâmica de construção e o valor considerável associado ao edificado e às infraestruturas instaladas.
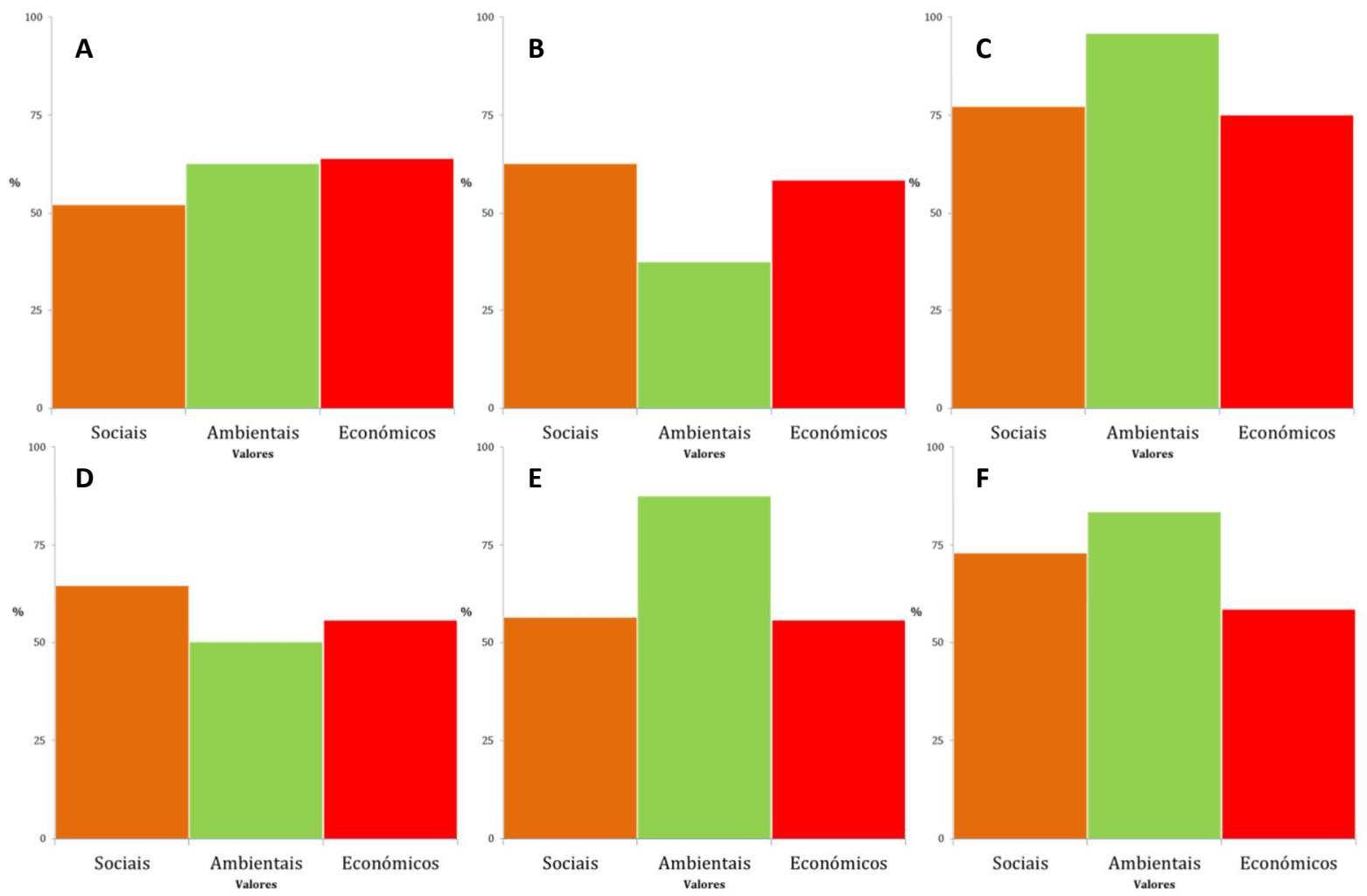

Figura 8 - Avaliação dos valores e recursos nas aldeias do projeto "Aldeias com Futuro" A - Canadelo; B - Cruzeiro; C - Gralheira; D - Loivos do Monte; E - Panchorra; F - Travanca do Monte

$\mathrm{Na}$ aldeia de Cruzeiro identifica-se um conjunto significativo de valores ambientais e económicos. Nos valores sociais destaca-se o peso da demografia, com uma percentagem de população jovem superior à média nacional e poucos sinais de envelhecimento. Também as relações de vizinhança e a vinculação à aldeia são importantes, apesar do associativismo e da ajuda em caso de necessidade serem pouco significativos. No domínio ambiental os registos são baixos, em especial no que diz respeito ao património construído, onde não há valores significativos. No conjunto de valores económicos destaca-se a dimensão do edificado e das infraestruturas e ainda o impacto dos serviços na aldeia ou o peso da agropecuária orientada para o autoconsumo. 
A aldeia da Gralheira é claramente uma aldeia com futuro, apresentando um conjunto muito significativo de valores sociais, ambientais e económicos. Os valores sociais são diversos e resultam duma grande vinculação ao território e da preservação e valorização de boas relações de vizinhança e de várias tradições, saberes e conhecimentos. Regista-se apenas algum défice no campo da demografia, associado especialmente ao despovoamento. No plano ambiental há vários valores naturais e construídos. Por fim, os valores económicos também são significativos, traduzidos numa boa rede de infraestruturas, edifícios recentes e em bom estado de conservação, produção pecuária que consegue entrar no mercado e rede interessante de atividades do sector terciário, com destaque para a restauração.

Em Loivos do Monte destacam-se os valores sociais, associados à dinâmica demográfica e ao coletivo, com fortes relações de vizinhança e entreajuda e um efetivo populacional em acentuado processo de despovoamento mas em que a percentagem de população jovem é superior à média nacional. No campo dos valores ambientais ressalta a antiguidade do povoamento, ao passo que o estado de conservação do edificado e o sistema produtivo (comercial e de autoconsumo) estruturam os principais valores económicos.

A aldeia de Panchorra destaca-se por um conjunto muito significativo de valores ambientais, associados a uma grande relevância do património natural - na sua diversidade, incluindo qualidade da floresta e presença de elementos de fauna, flora, geologia e recursos hídricos - e do património construído, seja pela sua antiguidade, pelo valor do conjunto ou pelo conforto do espaço público. No campo dos valores sociais, os principais recursos dizem respeito às relações de vizinhança e à vinculação ao território, em contraste com um contexto demográfico de perda. No plano económico deve registar-se a boa infraestruturação do espaço, as condições de habitabilidade dos edifícios e um sistema produtivo associado à atividade agropecuária (comercial e autoconsumo).

Em Travanca do Monte há um conjunto muito significativo de valores sociais e ambientais que podem sustentar o futuro da aldeia. O conjunto de valores sociais é marcado pela força das dimensões de demografia e relações de vizinhança, verificando-se até que é a única das seis aldeias que regista crescimento populacional entre 2001 e 2011, apresentando uma percentagem considerável de população jovem. O conhecimento e a ajuda entre os moradores são fortes, observando-se também uma grande vinculação à aldeia por parte dos emigrantes. No plano ambiental os valores são diversificados e estão associados a um conjunto alargado de recursos naturais, com um vasto leque de oportunidades para 0 
desenvolvimento no que respeita ao património edificado, designadamente na qualidade do núcleo de povoamento e em especial do seu espaço público. Os valores económicos são menos relevantes, estando associados especialmente ao valor do edificado e à atividade agropecuária.

\section{Conclusões}

Há muitos problemas e potencialidades nas aldeias. Todavia, seria bom deixarem-se as visões a preto e branco, do despovoamento "inevitável" ou da "turistificação", desejada por muitos e estigmatizada por outros, bem como outros discursos relativamente pobres, quando verificamos a complexidade das situações, a qual, por sua vez, não serve para esconder a evidente vantagem de ação política. No estudo que realizamos para as três grandes serras da Comunidade Intermunicipal do Tâmega e Sousa, em território de "Douro Verde", consideram-se três cenários distintos para o desenvolvimento de aldeias de montanha, tendo como objetivo principal a melhoria da qualidade de vida dos residentes. No Marão, na Aboboreira e no Montemuro identificou-se um conjunto de oportunidades de desenvolvimento que, tal como resultou de reuniões de envolvimento, com a associação de desenvolvimento local (Dolmen), os municípios e um grupo alargado de agentes locais, passaram a ser assumidas como centrais para a construção e implementação de ação num conjunto restrito de aldeias.

No quadro desta estratégia optou-se por privilegiar intervenções integradas, orientadas para a melhoria da qualidade de vida dos residentes - sejam os que já aí residem, sejam novos residentes - e para o fortalecimento de uma rede de aldeias, onde se partilhem experiências (de requalificação do património, de valorização das construções e do espaço público, de valorização económica e cultural de práticas tradicionais e de qualificação e diversificação de atividades económicas e dos recursos endógenos) e se desenvolva uma aprendizagem coletiva que permita também alargar esta experiência a outros contextos territoriais de baixa densidade.

Neste pressuposto e considerando o princípio do "investimento mínimo - efeito máximo", a estratégia estruturou-se em três domínios de intervenção: constituição de rede de agentes locais; reabilitação e qualificação arquitectónica, e programa estratégico, cujas propostas estão disponíveis em http://aldeiascomfuturo.com. 
No primeiro domínio, foi formalmente constituída uma rede de agentes locais - a rede "Aldeias com Futuro" -, integrando todos os parceiros que manifestaram interesse num envolvimento comprometido com o projeto. A rede será alvo de permanente atualização, com possível alargamento a outras experiências e agentes de desenvolvimento no país. Para a sua animação e dinamização foi constituída (em julho de 2015) uma plataforma eletrónica de apresentação do projeto e para troca de informação, debate e reflexão participada.

O programa de reabilitação e qualificação arquitetónica foi desenvolvido de forma a promover intervenções integradas no edificado e no espaço público, privilegiando soluções de baixo custo, adaptadas às especificidades e valores de cada aldeia e lugar no seu interior. Consideraram-se domínios de intervenção privilegiados a instalação de sinalização adequada, a criação ou organização de espaços de aparcamento automóvel, a repavimentação de algumas vias e a reabilitação de edificado degradado. As propostas encontram-se categorizadas por níveis de prioridade que refletem, em primeiro lugar, a urgência da intervenção face a uma situação particularmente grave e, em segundo, o potencial valor de desenvolvimento, numa perspectiva de custo-benefício.

O programa estratégico de intervenção foi desenhado em parceria, assumindo alguns temas como centrais e um sistema de avaliação de valores e recursos, agrupados em sociedade, ambiente e economia. Aponta para a necessidade de combater os pontos fracos e potenciar os pontos fortes, aproveitando oportunidades associadas à possibilidade de financiamento e envolvimento de parceiros privados, através de soluções integradas, centradas no território e na sua população, com soluções adaptadas às especificidades de cada aldeia, sem prejuízo de intervenções em rede.

\section{Referências}

ASCHER, F. (2002). L'émergence de la societé hipertexte. Futuribles: 8.

BIANCHIN, S., E. RICHERT, H. HEILMEIER, M. MERTA, CH. SEIDLER, 2011. Landscape metrics as a tool for evaluating scenarios for flood prevention and nature conservation. Landscape Online 25, 1-11. DOI:10.3097/LO.201125

CCE (2001). European Governance: a White Paper. C. Europeia, Comissão Europeia: 35.

DALE V., KLINE K., KAFFKA S, LANGVELD J., 2013. A landscape perspective on sustainability of agricultural systems. Landscape Ecology 28:1111-1123. DOI 10.1007/s10980-012-9814-4

EVERARD M and WATERS R. (2013). Ecosystem services assessment: How to do one in practice (Version 1, October 13). Institution of Environmental Sciences, London. www.ies-uk.org.uk/resources/ecosystemservicesassessment 
HALL, P. (2014) Creating transport corridors: refreshing the places other transport hasn't reached. Regions and Cities. Where Policies and People Meet, OECD, pp 211-219.

HALL, T. The entrepreneurial city: new urban politics, new urban geographies, Progress in Human Geography, June 1996 20: 153-174

HEALEY, P. (2004). "The treatment of space and place in the new strategic spatial planning in Europe." International Journal of Urban and Regional Research 28(1): 45-+.

JELLINEK S., PARRIS K., DRISCOLL D., DWYER P., 2013. Are incentive programs working? Landowner attitudes to ecological restoration of agricultural landscapes. Journal of Environmental Management 127 (2013) 69-76

MARQUES, H. (2015) O verde produtivo na AMP no horizonte 2020, GOT, no 7, pp. 213-229

MICHAILIDOU, E., 2012. Integrated Land Consolidation: A community-based initiative for Greek mountainous regions, In Regional Insights, 3:1, 18-20.

http://rsa.tandfonline.com/doi/abs/10.1080/20429843.2012.10510721

OCDE (2006). The New Rural Paradigm: Policies and Governance. OCDE 2006. DOI:10.1787/9789264023918-en

ODPM (2003). Sustainable Communities: building for the future. London, ODPM.

OPDAM P., NASSAUER J., WANG Z., ALBERT .C, BENTRUP G., CASTELLA J., MCALPINE C., LIU J., SHEPPARD S., SWAFFIELD S., 2013. Science for action at the local landscape scale. Landscape Ecol (2013) 28:1439-1445. DOI 10.1007/s10980-013-9925-6

PINTO, João Paulo (2015) Os "neo -rurais" na região do "Douro Verde": Impacte social, económico e cultural. Dissertação de Mestrado em Riscos Cidades e Ordenamento do Território, Faculdade de Letras da Universidade do Porto, Porto.

REED, M.S., ARBLASTER, K., BULLOCK, C., BURTON, R.J.F., DAVIES, A.L., HOLDEN, J.,HUBACEK, K., MAY, R., MITCHLEY, J., MORRIS, J., NAINGGOLAN, D., POTTER, C., QUINN, C.H.,SWALES, V., and THORP, S. NOVEMBER. Using scenarios to explore UK upland futures. 2009. Futures, v.41, pp.619-630. doi:10.1016/j.futures.2009.04.007

SASSEN, S. (2006). Cities in a World Economy. London, Sage Publications.

SHUCKSMITH M, RONNINGEN K. 2011. The uplands after neoliberalism? The role of the small farm in rural sustainability. Journal of Rural Studies 27:275-287.

SILVA, Ângela (2011); Inovação, empreendedorismo e agentes locais na base de estratégias de desenvolvimento territorial: reflexões a propósito da aplicação do programa PROVERE no Tâmega. Actas do VIII Congresso da Geografia Portuguesa. Lisboa, 2011 (publicação em CD- ROM ISBN: 978-972-99436-4-5)

SOLIVA, R., K. RONNINGEN, I. BELLA, P. BEZAK, T. COOPER, B. FLO, P. MARTY, C. POTTER, Envisioning Europe's upland futures: stakeholder responses to scenarios for Europe's mountain landscapes, Journal of Rural Studies 24 (2008) 56-71. doi:10.1016/j.futures.2009.04.007

TUDOR C., 2014. An Approach to Landscape Character Assessment. Natural England (www.gov.uk/naturalengland)

Sítios da internet

http://www.aldeasabandonadas.com/

http://www.aldeiascomfuturo.com/

http://www.dolmen.co.pt/

http://www.economia.elpais.com/economia/2015/07/31/vivienda/1438335315_044590.html

http://www.mirror.co.uk/news/world-news/sale-entire-italian-village-complete-5257520 